\title{
3D crosshole ERT for aquifer characterization and monitoring of infiltrating river water
}

\author{
Ilaria Coscia ${ }^{1}$, Stewart A. Greenhalgh ${ }^{2}$, Niklas Linde ${ }^{3}$, Joseph Doetsch ${ }^{1}$, Laurent Marescot ${ }^{1}$, \\ Thomas Günther ${ }^{4}$, Tobias Vogt ${ }^{5}$, and Alan G. Green ${ }^{1}$
}

\begin{abstract}
The hydrogeological properties and responses of a productive aquifer in northeastern Switzerland are investigated. For this purpose, 3D crosshole electrical resistivity tomography (ERT) is used to define the main lithological structures within the aquifer (through static inversion) and to monitor the water infiltration from an adjacent river. During precipitation events and subsequent river flooding, the river water resistivity increases. As a consequence, the electrical characteristics of the infiltrating water can be used as a natural tracer to delineate preferential flow paths and flow velocities. The focus is primarily on the experiment installation, data collection strategy, and the structural characterization of the site and a brief overview of the ERT monitoring results. The monitoring system comprises 18 boreholes each equipped with 10 electrodes straddling the entire thickness of the gravel aquifer. A.multichannel resistivity system programmed to cycle through vari-
\end{abstract}

ous four-point electrode configurations of the 180 electrodes in a rolling sequence allows for the measurement of approximately 15,500 apparent resistivity values every $7 \mathrm{~h}$ on a continuous basis. The 3D static ERT inversion of data acquired under stable hydrological conditions provides a base model for future time-lapse inversion studies and the means to investigate the resolving capability of our acquisition scheme. In particular, it enables definition of the main lithological structures within the aquifer. The final ERT static model delineates a relatively high-resistivity, low-porosity, intermediate-depth layer throughout the investigated aquifer volume that is consistent with results from well logging and seismic and radar tomography models. The next step will be to define and implement an appropriate time-lapse ERT inversion scheme using the river water as a natural tracer. The main challenge will be to separate the superposed time-varying effects of water table height, temperature, and salinity variations associated with the infiltrating water.

\section{INTRODUCTION}

Electrical resistivity tomography (ERT) is a popular subsurface imaging technique in hydrogeological, environmental, and civil engineering investigations (e.g., Daily et al., 2005; Kruse et al., 2006; Robinson et al., 2008; Sjödahl et al., 2009). Crosshole implementations of the technique offer improved resolution and depth penetration over surface surveying (e.g., Daily and Owen, 1991; Bing and Greenhalgh, 2000; Chambers et al. 2007). Time-lapse studies, in which repeat measurements are made at different time intervals to track changes in the subsurface properties, have been performed for salt tracer experiments (Slater et al., 2000; Kemna et al., 2002; Singha and Gorelick; 2005; Cassiani et al., 2006; Wilkinson et al., 2010, and references therein) and for the monitoring of steam injection (Ramirez et al., 1993), environmental remediation (Daily and Ramirez, 1995; LaBrecque et al., 1996a), biostimulation (Lane et al., 2006), watershed characterization (Miller et al., 2008) and various other processes (Binley et al., 2002; Deiana et al., 2007; Nimmer et al., 2007).

Manuscript received by the Editor 27 July 2010; revised manuscript received 28 October 2010; published online 21 March 2011.

${ }^{1}$ ETH Zürich, Institute of Geophysics, Zürich, Switzerland. E-mail: coscia@aug.ig.erdw.ethz.ch; doetsch@aug.ig.erdw.ethz.ch; laurent@tomoquest.com; green@aug.ig.erdw.ethz.ch.

${ }^{2}$ ETH Zürich, Institute of Geophysics, Zürich, Switzerland and University of Adelaide, Department of Physics, Adelaide, Australia. E-mail: greenhalgh@ aug.ig.erdw.ethz.ch; stewart.greenhalgh@adelaide.edu.au.

University of Lausanne, Institute of Geophysics, Lausanne, Switzerland. E-mail: niklas.linde@unil.ch.

${ }_{5}^{4}$ Leibniz Institute for Applied Geophysics, Hannover, Germany. E-mail: Thomas.Guenther@liag-hannover.de.

5Eawag Swiss Federal Institute of Aquatic Science and Technology, Duibendorf, Switzerland. E-mail: tobias.vogt@eawag.ch. (c) 2011 Society of Exploration Geophysicists. All rights reserved. 
In this paper, we describe results of a novel 3D crosshole resistivity monitoring experiment designed to investigate the hydrological properties and infiltration patterns of a producing gravel aquifer in direct connection with an adjacent river in northeastern Switzerland. Rainwater generally contains significantly lower concentrations of total dissolved solids (i.e., ions) than river water. As a consequence, strong precipitation in the catchment can cause the electrical resistivity of river water to increase. At our experimental site, high discharge events cause strong fluctuations of the river water electrical properties (increase in electrical resistivity). Therefore, the river water that continuously infiltrates the aquifer can be used as a natural tracer to delineate the more hydraulically conductive sections of the aquifer and, as shown by Cirpka et al. (2007), to determine traveltime distributions.

Our research is part of a much larger project (RECORD REstored CORridor Dynamics) aimed at assessing and modeling coupled hydrological, ecological, and biochemical effects of river restoration (http://www.cces.ethz.ch/projects/nature/Record). In the project, there are two study sites: one along a restored section (Neunforn) and one along an unrestored section (Widen) of the Thur River in Switzerland (Figure 1). Here, we restrict our attention to an initial hydrogeophysical study at the unrestored site. The eventual 4D ERT model should provide new constraints for understanding interactions between the river and the connected aquifer. As summarized in the following paragraphs, our study differs from most earlier investigations in four ways: (1) the full 3D inversion of an extensive crosshole data set acquired using electrodes deployed in many boreholes; (2) an inversion strategy that accounts for surface and sediment layer topography, borehole inclinations, and the electrical properties of the borehole fluids; (3) the use of river water as a natural tracer to investigate an adjacent aquifer, and (4) continuously recorded data over a long time period at a sufficiently high sample rate to capture the transient process.

ERT has previously been used for studying the interactions between rivers and their surroundings and for improving the

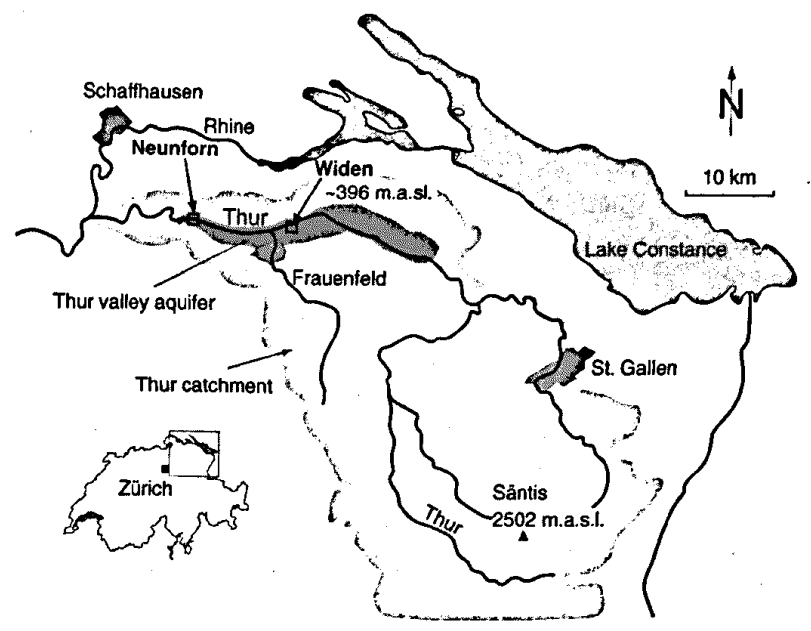

Figure 1. Location of the Thur catchment, Thur valley aquifer, and Neunforn and Widen test sites in northeastem Switzerland. Modified from a figure prepared by Swisstopo (Swiss Federal Office of Topography) m.a.s.l., meters above sea level. modeling of fluvial systems. For example, Crook et al. (2008) used the technique to obtain information about the continuity and structure of stream-bed sediments. They used information provided by a static resistivity model obtained from an ERT inversion of surface 2D geoelectrical data. Nyquist et al. (2008) identified a zone of groundwater seepage into a river by combining the structural information about the site with that provided by the comparison of 2D ERT images along the riverbed at low and high river stage conditions. Recently, Ward et al. (2010) investigated to what extent surface 2D time-lapse ERT images, when combined with stream tracer experiments, can provide information about temporal and spatial dynamics in the hyporheic zone. Crosshole ERT, which is the basis of our work, usually yields more definitive information than surface ERT, especially if conducted in a time-lapse fashion. Previous such studies (e.g., Singha and Gorelick, 2005; Slater and Binley, 2006; Kuras et al., 2009; Müller et al., 2010; Wilkinson et al., 2010 ), even if based on 3D inversions, have generally only involved sequential 2D measurements (i.e., between just one pair of boreholes at a time). Furthermore, the inversions have seldom been performed on data from more than four boreholes because of the inability of standard inversion software to handle large 3D data sets. In our study, we test a new acquisition and inversion strategy for carrying out a fully $3 \mathrm{D}$ crosshole ERT experiment using electrodes located in 18 boreholes. We utilize a finite-element modeling (FEM) and inversion code based on unstructured meshes that allows us to incorporate typical complexities associated with surface topography, sharp boundaries, and the boreholes themselves.

Most previous time-lapse ERT studies have been aimed at improving our understanding of subsurface solute transport by using time-varying electrical responses related to known injections of saline tracers into aquifers or known injections of water into the vadose zone (e.g., Slater et al., 2000; Singha and Gorelick, 2005, Slater and Binley, 2006, Müller et al., 2010, Wilkinson et al., 2010). Only a few studies have taken advantage of pre-existing electrical contrasts between the properties of subsurface fluids, such as those related to movements of contaminant plumes (Slater and Sandberg, 2000; Nimmer et al. 2007) or those related to salt water/fresh water contacts within coastal aquifers (e.g., Slater and Sandberg, 2000; Acworth and Dasey 2003; de Franco et al., 2009; Maurer et al., 2009; Ogilvy et al., 2009). In other investigations (e.g., Hauck, 2002; Jayawickreme et al., 2008; Yeh et al., 2008) natural occurring contrasts have been exploited. However, as far as we know, no previous geophysical researchers have used the electrical properties of river water as a natural tracer to investigate aquifer response.

Time-lapse ERT usually involves frequently repeated measurements over a short period (e.g., Wilkinson et al., 2010) or sparse measurements at infrequent intervals over a long period to determine seasonal variations in some property (e.g., French and Binley, 2004; Hayley et al., 2009; Krautblatter et al., 2010). The study presented here is one of only a few examples (see also de Franco et al., 2009 and Ogilvy et al., 2009) of a long-term ERT monitoring study (approximately 1 year of data have been collected in our case) with short-period data sampling (one data set of approximately 15,500 data points is acquired every $7 \mathrm{~h}$ on a continual basis). This permits the investigation of aquifer infiltration and solute transport after river-flooding events. It also enables us to investigate seasonal variations in electrical resistivity (e.g., same 
water height but different water resistivity because of snow melt, de-icing chemicals, or water temperature changes).

We begin by introducing the 18-borehole, 180-electrode 3D monitoring system and the geology of the site. Next, we describe the different electrode combinations and procedures used for remote data acquisition and then show the electrical signature of a typical flood event from the summer of 2009 , which produces time series of clear apparent resistivity anomalies. Finally, we present the results of a static 3D ERT inversion for subsurface structure, incorporating various complexities such as surface and layer topography, decoupling of regularization across sharp layer boundaries, the borehole fluid effect, and borehole deviations. Such 3D images will be used as initial and reference models for future time-lapse inversion investigations.

\section{WIDEN FIELD EXPERIMENT}

\section{Site description}

The Widen study site (Figure 1) is located in northeastern Switzerland along the Thur River (a tributary of the Rhine River), which has a total length of approximately $127 \mathrm{~km}$ and a catchment area of approximately $1750 \mathrm{~km}^{2}$. Because of the pre-alpine character of the upper Thur catchment that includes Mount Säntis (2502 $\mathrm{m}$ above sea level) and because of the absence of any natural or man-made reservoirs, the Thur River exhibits fluctuations in discharge and water table height similar to unregulated alpine rivers. Base flow has its maximum during snowmelt in spring, but flow peaks can occur at any time of the year in response to rainfall in the upper catchment (low discharge: $3 \mathrm{~m}^{3} / \mathrm{s}$; mean discharge: 20 $50 \mathrm{~m}^{3} / \mathrm{s}$; peak discharge: up to $1000 \mathrm{~m}^{3} / \mathrm{s}$; Federal Office for the Environment, http://www.bafu.admin.ch/publikationen/01005).

Our study site is located within the central Thur floodplain (altitude approximately $400 \mathrm{~m}$ above sea level, $2 \mathrm{~km}$ wide, and $30 \mathrm{~km}$ long), where the Thur River flows from east to west along the northern edge of a valley (Figure 1) that formed during the Pleistocene period by glaciers cutting into the underlying Tertiary bedrock. After the glaciers retreated, a lake was left behind and subsequently filled with fine silt and clay sediments. These sediments now constitute the aquitard at this location. The productive aquifer above the clay comprises a $6.5-$ to $7-\mathrm{m}-$ thick layer of gravel and sand that is overlain by approximately $3 \mathrm{~m}$ of alluvial loam (see Figure $2 \mathrm{~b}$ ). During the $1890 \mathrm{~s}$, this area of the Thur River was channelized. The main channel is approximately $40-45 \mathrm{~m}$ wide. There is no overbank on the northern side because of a prominent hillslope that acts as a natural barrier at high discharge, whereas on the southern side there is a levee approximately $130 \mathrm{~m}$ from the river. Behind this levee, a side channel has been constructed to capture discharge from tributaries and drain the nearby agricultural land. There is a pumping well approximately $80 \mathrm{~m}$ from the levee that produces approximately $9000 \mathrm{~m}^{3} / \mathrm{d}$ of drinking water for the 30,000 inhabitants of a nearby town (Frauenfeld in Figure 1).

At our local study site, the Thur River infiltrates year-round into the aquifer (Cirpka et al., 2007), with a shallow local flow component at the top related to the infiltration of river water and a regional flow component in the lower sections following the main direction of the valley. The overall direction of groundwater flow, influenced also by pumping well activity, is from northeast to southwest with fairly high velocities ranging between 1 and $50 \mathrm{~m} / \mathrm{d}$. The hydraulic conductivity of the aquifer is estimated from pumping and slug tests (Diem et al., 2010) to range between $10^{-3}$ and $10^{-2} \mathrm{~m} / \mathrm{s}$. Depending on the water table position, the aquifer displays unconfined and confined behavior.

\section{Experimental setup and field instrumentation}

The main direction of groundwater flow, the hydrogeological parameters described in the previous section, and surface ERT surveys to delineate the major vertical and horizontal resistivity variations at the site guided the design of the electrical monitoring experiment. Eighteen boreholes at a nominal spacing of $3.5 \mathrm{~m}$ (Figure $2 \mathrm{a}$ ) were installed with depths varying from 10 to $12 \mathrm{~m}$. Four of them (B2, B3, C2, C3) are located at the corners of a square with $5-\mathrm{m}$ side lengths and have $11-\mathrm{cm}$ diameters to enable crosshole seismic and radar measurements to be made (Doetsch et al., 2010b) and to obtain samples in the coarse-grain sedimentary formation (Diem et al., 2010). The remaining 14 boreholes with $5-\mathrm{cm}$ diameters were drilled using a direct-push machine. The entire borehole installation covers a surface area of $10 \times 15 \mathrm{~m}$, which together with the $6.5-$ to $7-\mathrm{m}$ thickness of the aquifer defines an investigation volume of approximately $1000 \mathrm{~m}^{3}$. All 18 boreholes are lined with polyvinyl chloride (PVC) or high-density polyethylene (HDPE) casing that is slotted along the aquifer section (see Figure $2 \mathrm{~b}$ ). Each borehole contains 10 stainless steel cylindrical electrodes spaced $0.7 \mathrm{~m}$ apart. The electrodes are each equipped with rubber disk packers fixed above and below (Figure 3c) to reduce as much as possible the vertical flow of water and partially focus the electric current flow outward into the formation. The electrodes

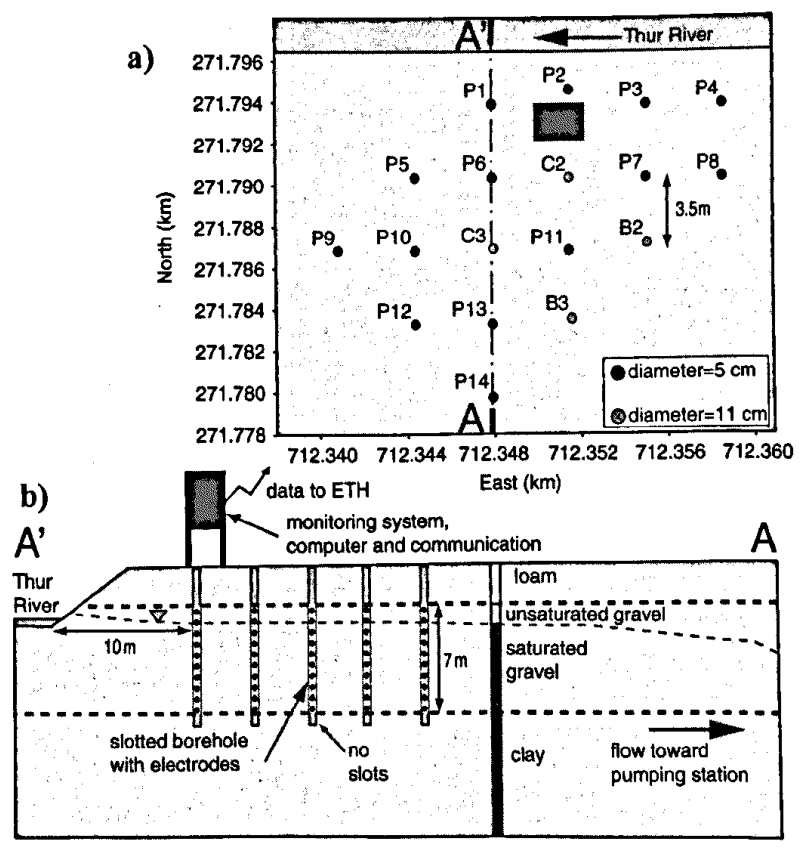

Figure 2. (a) Plan view of part of the Widen site showing borehole positions in Swiss grid coordinates with respect to the river and flood-proof hut (square). (b) Vertical section $A^{\prime}-A$ through the test site showing electrode installations, stratigraphy, groundwater table, and flow direction. Location of the section is shown in panel a. 
are connected via waterproof cables to the recording system (Figure 3d). The lowest nine electrodes are usually below the water table, providing good electrical connection to the sedimentary formation through the borehole water and slotted casing. The top electrode can only be used when it makes electrical contact during periods of high water level.

A flood-proof hut at the site houses the recording system (Figures $2 \mathrm{~b}$ and $3 \mathrm{a}$ and $3 \mathrm{e}$ ) and provides access to mains power and a wireless link for data transmission to ETH Zurich. The resistivity instrument provides 10-channel recording capability and is interfaced to a switching unit that allows up to 192 electrodes to be connected and automatically selected according to a predetermined sequence. Software is used to control the recording unit from a field computer also housed in the elevated floodproof hut. It is possible to preprogram the sequence of measurements at user-defined timing intervals and to store the recorded voltage data (and other information, such as current strength, electrode geometry) directly on the PC hard disc. Wireless connection to the field computer enables the measurements to be controlled in real time and the data downloaded from the PC disc to a computer back at ETH Zürich for back-up, quality control, and processing purposes.

Geophysical well logs (natural gamma, gamma-gamma, and neutron-neutron) run in each borehole define the gravel-clay interface in a more precise way than just using the disturbed cores retrieved during the borehole drilling campaign. The logs are useful in evaluating the static inversion model results. To reduce systematic errors associated with incorrect positions of the electrodes, the trajectories of each borehole were determined by a three-axis magnetometer and three-axis accelerometer downhole system. In addition to the electrodes, 14 multisensor devices and integrated data loggers are installed in six of the boreholes at different depths. These multisensors measure tem-

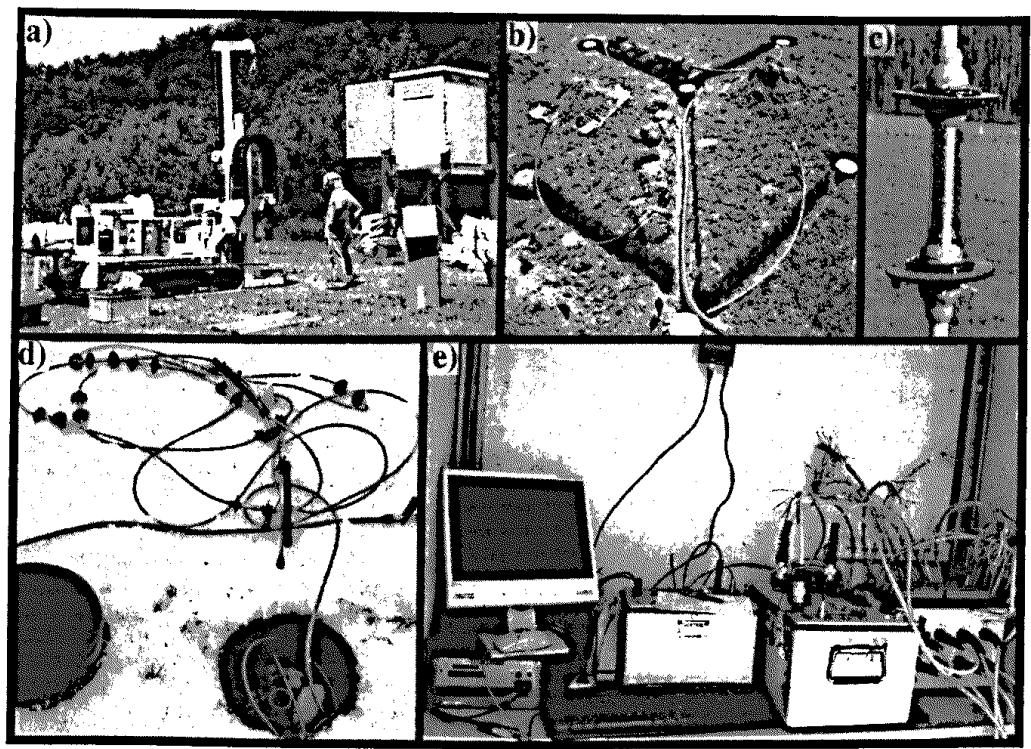

Figure 3. (a) Direct-push drilling rig and, on the right, flood-proof hut. (b) Underground pipes connecting the geoelectric cables in the 18 boreholes with the measuring system inside of the flood-proof hut. (c) Electrode with "packers." (d) Geoelectric cable equipped for a 5 -cm borehole. (e) Field computer and components of the geoelectric acquisition system with a modem for wireless connection (top) inside of the flood-proof hut. perature, electrical conductivity, and the hydraulic head of the groundwater every $15 \mathrm{~min}$. This information will be vital for meaningful interpretations of the time-lapse ERT data.

\section{ERT data collection scheme}

To have a fast and fully 3D data-capture sequence, we designed, after some preliminary synthetic studies and taking into account the borehole fluid effect (Doetsch et al., 2010a), a circulating four-point measurement scheme with the current and potential bipoles split between multiple boreholes. The data collection sequence operates as follows (Figure 4). One current electrode (A) occupies only one of two allowed positions in the two central boreholes $\mathrm{Cl}$ and $\mathrm{C} 2$ (i.e., the third electrode position in borehole $\mathrm{C} 2$ or the sixth electrode position in borehole $\mathrm{C} 3$ - see Figure 2 for the borehole locations), and the other current electrode (B) is always in the same borehole as one potential electrode (M). This second current electrode can be at any one of three different depths (counting from the top: the second, fifth, and eighth electrodes), whereas the potential electrode in the same hole moves through three other depths (counting from the top: the third, sixth, and ninth electrodes). Finally, the remaining potential electrode (N) scans all of the positions in the boreholes immediately surrounding the one where the bipole BM is located (Figure 4b). This data collection scheme is repeated until all boreholes have been occupied once by the bipole BM and the remaining mobile potential electrode $\mathrm{N}$ has created all possible electrode combinations as described above (see Figure $4 \mathrm{c}$ ).

This scheme is optimized to take advantage of the 10 independent channels of the recording system. A complete circulating sequence of approximately 15,500 data values (different electrode configurations across all 18 boreholes) is collected in $7 \mathrm{~h}$. The process is then repeated so that the aquifer is being continually monitored.

\section{The river water as a natural electrical tracer}

The hydrological regime of the Thur River is characterized by rapid undamped fluctuations of water level along its entire course after precipitation in the upper catchment. Associated with these fluctuations are significant changes to the electrical resistivity of the river water. As it infiltrates the aquifer, it acts as a resistivity anomaly that can be used as a natural tracer in time-lapse ERT imaging.

Figure 5 provides an example of the monitoring capability of the ERT system to track the magnitude and changing nature of this propagating resistivity anomaly. The presented data are for a flood event in the summer of 2009. When the river discharge increases, the river water resistivity increases. This can be readily observed by comparing the curve that represents the average water table height variation in the aquifer (Figure 5c) with the two curves that represent changes in water resistivity in the boreholes measured by the point loggers (Figure 5a). We show results from two loggers: one in borehole 
P3 close to the river and the other in borehole P12 some distance from the river (for locations see Figure 2a). Note the time delay between the peaks on the dotted and dashed curves (Figure 5a), which clearly shows the transient nature of the infiltrating anomaly. It hits the borehole closest to the river half a day earlier than that $15 \mathrm{~m}$ further away, and the signal magnitude is damped with increasing distance from the river. Figure $5 \mathrm{a}$ also shows the apparent resistivity time series (black circles) measured using the electrode configuration depicted in Figure $5 \mathrm{~b}$. This is a typical example of the ERT data trend during and after all flood events. The effect of the higher resistivity of the infiltrating water is readily apparent from the $15 \%$ anomaly over a period of several days.

\section{FULL 3D CROSSHOLE STATIC INVERSION}

\section{Static inversion approach and features}

Our 3D static inversions were performed using the open-source code BERT that is based on an unstructured finite-element framework (Günther et al., 2006; Rücker et al., 2006; www.resistivity.net). It enabled all important aspects of the study site to be modeled in detail, including the surface topography, boreholes, and main geological boundaries (Figure 6).

The boreholes were explicitly modeled, taking into account their inclinations and declinations to correctly position all electrodes and reduce geometrical errors, which otherwise could be significant (Figure 6b). Doetsch et al. (2010a) showed that the conductive borehole fluid has a strong effect on crosshole electric measurements for most standard AM-BN and AB-MN electrode configurations. They also demonstrated that this effect could be removed by explicitly including the boreholes in the modeling and inversion. This is especially important if the boreholes are closely spaced, the borehole diameters are large, and the resistivity contrasts between the fluid and host rock are high.

The overall stratigraphy at the site is well established. The approximate layer thicknesses are known from the boreholes and geophysical well logs, and the average layer resistivities are estimated from surface resistivity surveys. Under low river water conditions, the unsaturated part of the aquifer is approximately $1 \mathrm{~m}$ thick. It presents a significant resistivity contrast with the underlying saturated part of the aquifer that strongly influences the voltage measurements. As a consequence, the actual height of the water table should be determined from the borehole data loggers and fixed in the inversion, without imposing smoothness constraints (regularization) across what is known to be a sharp boundary (i.e., the very thin capillary fringe of gravel). From synthetic tests, we ascertain that the presence of the unsaturated gravel makes the sensitivities of the crosshole ERT measurements to the surface loam layer almost negligible. Therefore, the surface loam is not included in the initial model, allowing us to reduce slightly the number of inversion parameters. In analogy with the saturated-unsaturated interface, the clay-gravel interface is a boundary across which there is an order of magnitude resistivity contrast, such that it is desirable not to impose smoothness constraints across it.

The unsaturated and saturated zones of the aquifer, the gravel and clay layers, and the boreholes themselves constitute different regions in the inversion domain shown in Figure 6. This allows us to assign different initial values and different inversion parameters to each zone and to disconnect the regularization between
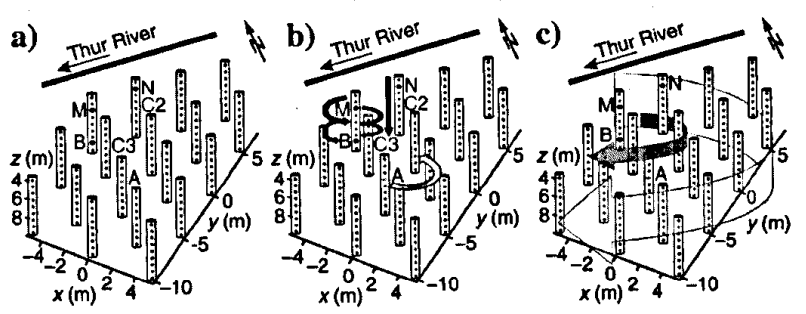

Figure 4. Illustration of how the configurations of the current electrodes $\mathrm{A}$ and $\mathrm{B}$ and potential electrodes $\mathrm{M}$ and $\mathrm{N}$ used in the geoelectric data acquisition system are circulated. (a) The four electrodes are always located in three different boreholes with $\mathrm{A}$ in only two possible positions in the two central boreholes. B and $\mathrm{M}$ always share a borehole and $\mathrm{N}$ is always in one of the boreholes immediately adjacent to them. (b) Movement of the electrodes is repeated for each borehole occupied by the current-potential (B-M) bipole. (c) Scheme repeated throughout the electrode array until the roving bipole has occupied all boreholes not occupied by the fixed current electrode.
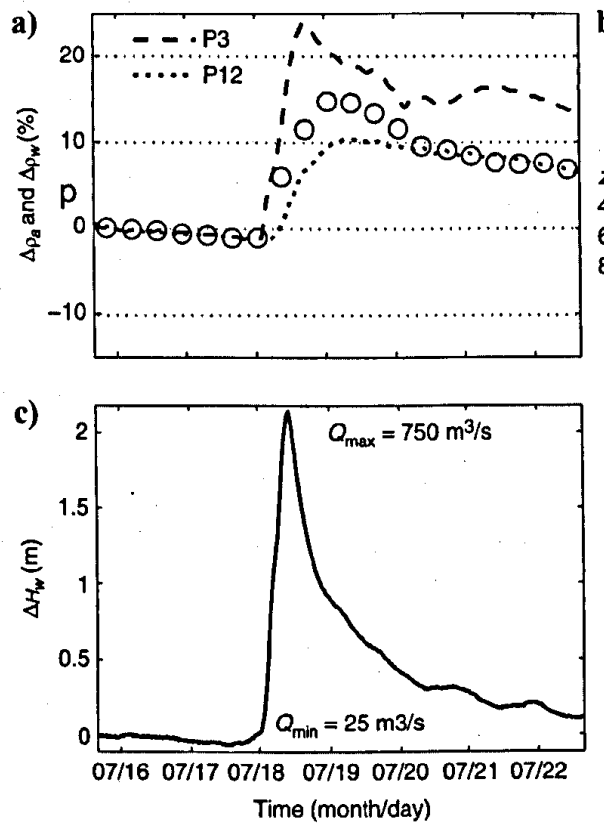

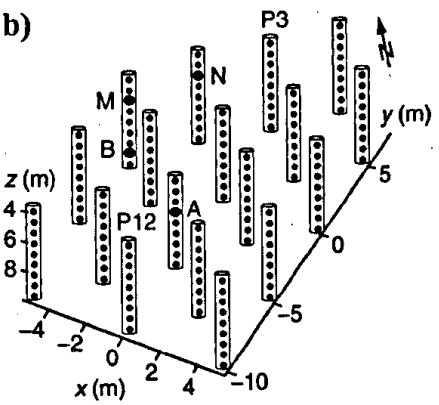

Figure 5. (a) Comparison between time series of relative apparent resistivity variations (black circles) during a strong hydrological event, and relative electrical-resistivity variations of the water at two locations (dotted and dashed curves - P3 and P12 near and far from the river, respectively). (b) ERT configuration used to record the apparent resistivity data shown in panel a. (c) Mean variations of the water table position within the electrode array together with minimum and maximum discharges during the event. 
the zones (see Table 1). A layered 1D model of unsaturated gravel $\left(\rho_{m 0}=700 \Omega \mathrm{m}\right)$ underlain sequentially by saturated gravel $\left(\rho_{m 0}=250 \Omega \mathrm{m}\right)$ and clay $\left(\rho_{m 0}=25 \Omega \mathrm{m}\right)$ constitutes a reasonable starting model for the inversions (Figures 2 and $6 \mathrm{~b}$ ).

The inversion domain (Figure 6b), in which the above-mentioned initial model is defined, is embedded within a much larger forward modeling domain (Figure 6a). The former is kept small to reduce the size of the inversion problem; it extends horizontally approximately $2 \mathrm{~m}$ outward from the most external boreholes and vertically to include the unsaturated gravels and approximately $2 \mathrm{~m}$ of the clay aquitard (Figure 2b). The latter needs to be large to avoid boundary effects and, for the same purpose, has boundaries controlled by mixed boundary conditions (Rücker et al., 2006). At each iteration of the inversion routine, the resistivity values defined in the inversion domain are laterally extrapolated into the forward modeling domain.

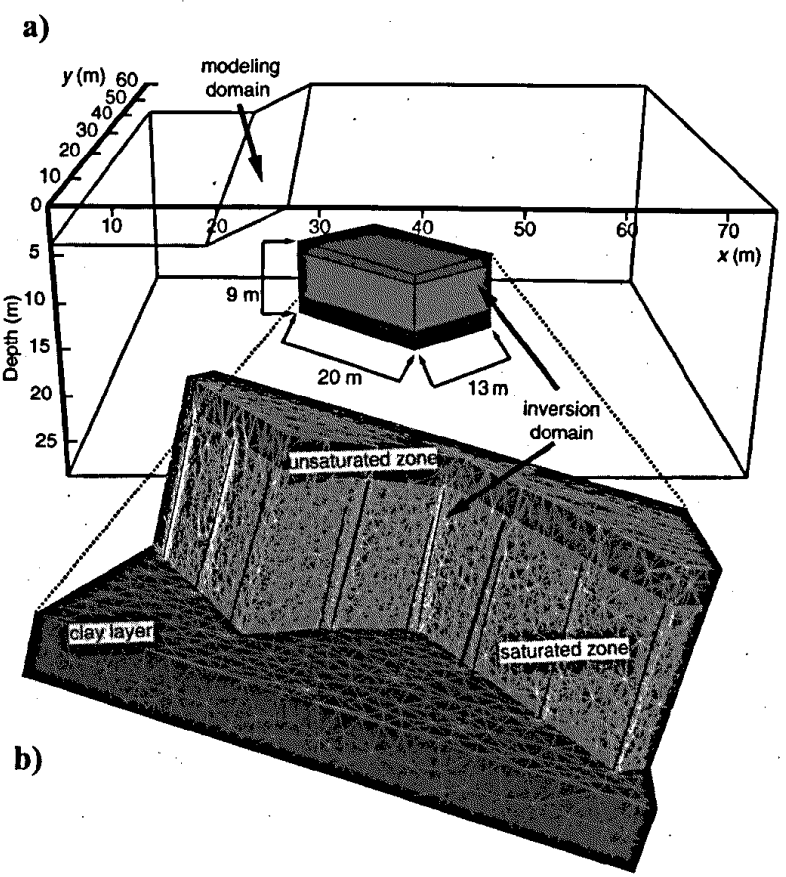

Figure 6. (a) Modeling domain with topography and the embedded inversion domain for the different regions (see Table 1), which shows the geometry of the input model for the inversion. (b) Unstructured parameter mesh, tilted boreholes, and input topography of the saturated-unsaturated gravel and gravel-clay interfaces of the inversion domain.
The approximately 205,500 tetrahedra of the mesh for the inversion domain were generated using the meshing code Tetgen (http:/tetgen.berlios.de/). This code allowed different mesh properties to be defined in each region of the domain. To precisely delineate the structures, we imposed a maximum volume of $0.05 \mathrm{~m}^{3}$ on all tetrahedra within the saturated aquifer (Figure $6 \mathrm{~b})$. The forward mesh created by the code BERT refined the inversion mesh (Rücker et al., 2006) to have approximately $1,800,000$ elements corresponding to approximately 300,000 nodes. Some of the cells $(9 \%)$ were very small $(<5-\mathrm{cm}$ side length) to represent the boreholes around which abrupt resistivity changes occurred. Accordingly, singularity removal (Blome et al., 2009) was not required. This was recognized after running several modeling and inversion tests, which demonstrated that the very fine mesh allowed the high potential gradients around the borehole sources to be accurately modeled.

We inverted for a logarithmic model function of the resistivity described as (Günther, 2004)

$$
m=\log \left(\rho-\rho_{\text {lower }}\right)-\log \left(\rho_{\text {upper }}-\rho\right),
$$

where $\rho_{\text {lower }}$ and $\rho_{\text {upper }}$ are lower and upper bounds defined for each region (see Table 1), respectively.

Within the aquifer, we used anisotropic smoothing that penalized variations in the horizontal directions more than in the vertical direction to enhance the expected subhorizontal layering in this region (see also Linde et al., 2006). This was achieved by calculating a weighting factor $W$ for the roughness matrix based on the vertical component of the normal vector $n_{z}$ on each boundary between each tetrahedron of the mesh. The formulation for each tetrahedron boundary $i$ is given by

$$
W_{i}=1+\left(w_{z}-1\right) \cdot n_{z},
$$

where $w_{z}$ is a user-defined factor that can vary in each region of the model. This along with all other parameters used in each region of the inversion model are listed in Table 1.

The data set selected for determining a static $3 \mathrm{D}$ resistivity model of the site was collected on 15 November 2009 during a period of stable hydrological conditions. The water level in the river was low and the groundwater table was approximately 4.2 $\mathrm{m}$ below the surface. Consequently, approximately $1 \mathrm{~m}$ of the aquifer was unsaturated. The approximately $22-\Omega \mathrm{m}$ electrical resistivity and approximately $8^{\circ} \mathrm{C}$ temperature of the water was similar on all of the borehole sensors.

First, we only considered configurations having electrode geometrical factors $K \leq \pm 1000$ as a protection against probable low signal-to-noise data. Then, from the raw apparent resistivity data, we excluded all data values having standard deviations greater than $1 \%$ based on repeat measurements or voltages less

Table 1. Inversion parameters used for each region of the model shown in Figure 7.

\begin{tabular}{lcccc}
\hline Region & $\begin{array}{c}\text { Initial model } \\
\text { resitivity } \rho(\Omega \mathrm{m})\end{array}$ & Regularization type & $\begin{array}{c}\text { Scaling factor } n \text { for the } \\
\text { regularization parameter }\end{array}$ & $\begin{array}{c}\text { Bounding values } \\
\rho_{\text {lower }}-\rho_{\text {upper }}(\Omega \mathrm{m})\end{array}$ \\
\hline Unsaturated gravel aquifer & 700 & Anisotropic smoothing $\left(w_{z}=0.3\right)$ & 1 & $50-2000$ \\
Saturated gravel aquifer & 250 & Anisotropic smoothing $\left(w_{z}=0.1\right)$ & 1 & $50-500$ \\
Aquitard (clay layer) & 25 & Anisotropic smoothing $\left(w_{z}=0.3\right)$ & 1 & $5-45$ \\
Boreholes & 22 & Isotropic smoothing $\left(w_{z}=1\right)$ & 10 & $10-50$ \\
\hline
\end{tabular}


than $1 \mathrm{mV}$. After that, we eliminated all data based on electrode configurations in which one or more of the electrodes were above the water table (i.e., those that had very high contact resistances). We also discarded all of the negative apparent resistivities because of the limitation of the inversion code in handling negative values. Furthermore, we rejected any apparent resistivities greater than $500 \Omega \mathrm{m}$ or smaller than $30 \Omega \mathrm{m}$. These upper and lower limits were set after first observing the frequency distribution (histogram) of apparent resistivities and considering the likely range of resistivities for saturated sandy gravel. Finally, approximately 12,000 data points (approximately $77 \%$ of the original data set) were used in an initial inversion aimed at defining the remaining outliers in the data set not removed in the previous data selection sequence (see later).

Finally, we apply an error model for weighting the data and the elements of the Jacobian matrix (sensitivities) during the inversion. The error (or uncertainty) for each voltage measurement is considered to consist of two parts (see LaBrecque et al., 1996b): a fixed absolute value of $0.1 \mathrm{mV}$ (set by the instrument precision) and a relative error of $2 \%$ of the measured value (although we did experiment with other values in the range of $1-4 \%)$. This yields an uncertainty of $\delta U=(0.1+0.02 U) \mathrm{mV}$, where $U$ is the recorded voltage in millivolts. When considering resistance or apparent resistivity as the input data, one should ideally take into account sources of errors related to the current strength and electrode positions, but these are judged to be much smaller than the voltage uncertainties. Moreover, the inversion code that we employ uses the logarithms of apparent resistivities $\log \left(\rho_{a}\right)$ rather than voltages or apparent resistivities themselves; therefore, the estimated errors in these quantities used in data weighting matrix should be computed from the calculus of small changes (i.e., $\delta\left(\log \left(\rho_{a}\right)\right)=\delta U / U=(0.1+0.02 U) / U$ ). Although time consuming, we recalculate the Jacobian matrix (slightly $<20 \mathrm{~GB}$ ) after each iteration of the inversion and apply a robust reweighting of the data according to their misfit. For this reason, the initial median data error $(2.02 \%)$ was, at the end of the inversion, slightly increased to $2.04 \%$.

We apply a regularization - parameter $\lambda=100$ with an upscaled smoothness factor for the borehole region of the model (see Table 1) for all regions. Tests were conducted with other $\lambda$ values in the range of 5-200. Conventional wisdom is to opt for the largest value consistent with being able to fit the data to within a specified tolerance (e.g., $2 \%$ ). Smaller values of $\lambda$ can introduce more detail in the model, some of which might be spurious, whereas overly large values yield excessively smooth models. We found that using values larger than 100 removed a small conductive feature that was independently known from the borehole logging (for further details about the error model and the choice of the regularization, see Günther, 2004).

After an initial inversion, we plotted the frequency distribution of data misfits and excluded those measurements lying outside of a threshold given by 5 times the standard deviation of the distribution. The final data set, corresponding to almost 11,000 data points, was inverted using the same parameters as for the initial inversion. The inversion run time on a $2.66-\mathrm{GHz}$ quadcore computer with $32 \mathrm{~Gb}$ of RAM was approximately $15 \mathrm{~h}$ and it converged to the specified tolerance level $\left(\chi^{2}=1\right)$ in six iterations.

\section{Results}

Figure 7 shows two vertical slices through the final 3D model volume corresponding to the saturated part of the aquifer - one close and mainly parallel to the river (Figure 7a) and the other mainly along the principal diagonal (Figure $7 \mathrm{~b}$ ). The top and bottom layers (not shown) of the entire model correspond to the unsaturated gravel and the clay aquitard, respectively.

A central zone within the saturated gravel that is approximately $50 \%$ more resistive (up to $320 \Omega \mathrm{m}$ ) than the upper and lower parts $(120-220 \Omega \mathrm{m})$ is clearly delineated in the tomogram. It has an average thickness of approximately $2 \mathrm{~m}$ and lies in the 5-5.5- to 7-7.5-m depth range. It appears to be horizontal and continuous throughout the investigated volume. Earlier inversions, which were run without horizontal smoothing, show slightly inferior continuity of the resistive layer but still recover the layer.

In the plane containing the line of boreholes that lie close to the river (Figure 7a), the tomogram contains a more conductive zone (in blue) of approximately $1-\mathrm{m}$ thickness. This zone is characterized by resistivities of approximately $130 \Omega \mathrm{m}$. It corresponds to a lens of fine sediments observed in the drill core of nearby boreholes ( $\mathrm{P} 2$ and $\mathrm{P} 3$ ). The resistive zone above this conductor appears less continuous, but this is probably caused

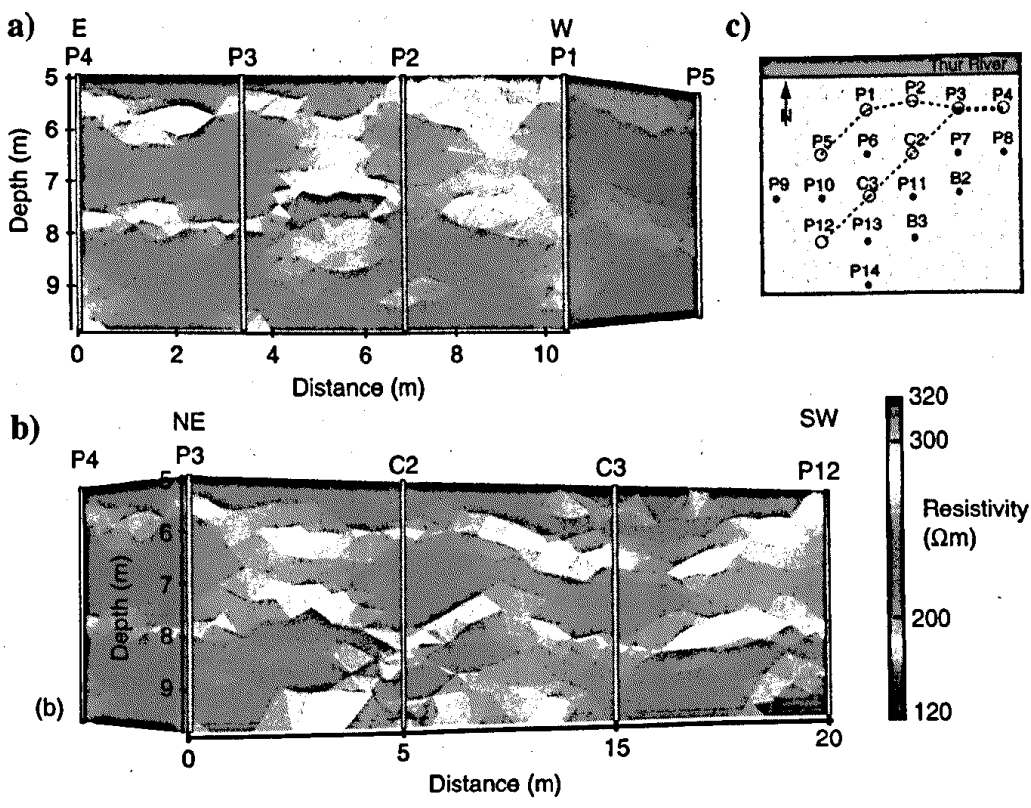

Figure 7. Resistivity cross sections extracted from the final inverted 3D model viewed from the river looking to the (a) south (green dashed line) and (b) southeast (violet dashed line). (c) The locations of boreholes corresponding to the two slices in panel a and $b$ are light blue. 
by the resolution pattern in this area, which is strongly influenced by the presence of the conductive zone; being relatively conductive, the current is drawn into the zone, thereby decreasing current density and hence sensitivity elsewhere.

Further from the river, a decrease in the resistivity of the lower part of the aquifer is observed (Figure $7 \mathrm{~b}$ ). This could represent a higher percentage of fine material in proximity to the underlying clay.

\section{DISCUSSION}

\section{Inversion aspects}

The distances between the boreholes are rather small $(3.5 \mathrm{~m})$, such that any borehole deviations need to be considered. Given the maximum tilt of some boreholes $\left(3^{\circ}\right)$, electrode mispositioning can be as much as $0.5 \mathrm{~m}$ if the boreholes are incorrectly assumed to be vertical. The tomograms would be adversely affected by such an error. We undertook some tests on a subset of data from eight of the boreholes and found that the central more resistive layer within the aquifer becomes noticeably less continuous when the boreholes are taken to be uniformly vertical instead of slightly tilted.

Doetsch et al. (2010a) investigated the borehole fluid effect, whereby the resistivity contrast between the borehole fluid and host rock can introduce false structure in the medium after inversion if the boreholes are not explicitly modeled. We have established from a series of inversion tests that for the particular unconventional electrode configurations that we used (see ERT data collection strategy), the borehole effect is minor. Very similar images (not shown) were obtained by ignoring the boreholes in the inversion process. This was partly a consequence of the relatively low resistivity contrast between the borehole fluid and the formation (8:1) and the fact that for most of the data collected with our unconventional configurations, the electrodes were placed in small-diameter holes $(5 \mathrm{~cm})$; there would be significant artifacts in the images if classical electrode configurations
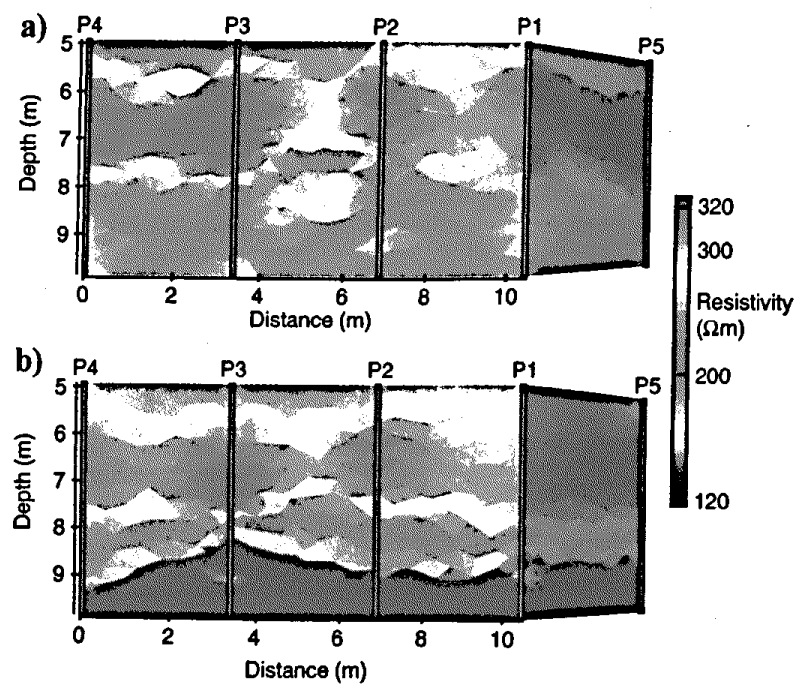

Figure 8. Cross sections extracted from inversion models in which the regularization between the layers is (a) decoupled (same as Figure 7a) and (b) not decoupled. (especially those having the current electrodes or the potential electrodes in the same borehole) were to be used, as in the study of Doetsch et al. (2010a). Inversions without including the boreholes require substantially fewer cells, thus reducing the memory requirements and the underdetermined nature of the problem.

Another important technical consideration is decoupling the regularization across the layers and preserving the sharp boundaries where they are known to exist (e.g., at the water table and at the clay-gravel interface). This entails setting the weight of the individual model cells to zero in the presence of a known boundary, resulting in sharp gradients at this position. Failure to do so produces significant smearing and artifacts in the images. For example, because the clay is 10 times less resistive than the saturated gravel, without layer decoupling the inversion produces an interface much shallower than that defined by the drill core and well-log data. This is illustrated in Figure 8, which shows inversion results along the section presented in Figure $7 \mathrm{a}$ adjacent to the river. The two plots correspond to inversions with (Figure 8a) and without (Figure 8b) decoupling the regularization between the layers. Notice the distortion of the clay interface and the disappearance of the low resistivity lens when no decoupling is applied. We performed several tests to confirm the importance of incorporating the correct positions of the known resistivity discontinuities. Surface topography should also, as a general rule, be incorporated in the inversion process, but from various synthetic tests we were able to establish that the zone of interest (saturated aquifer) is far enough away (i.e., at sufficient depth) that the measurements are only weakly sensitive to the sloping river bank topography.

We have also compared our inversion model with that obtained at the site by Doetsch et al. (2010b), who focused on jointly inverting seismic, radar, and ERT data sets acquired in the 11$\mathrm{cm}$-diameter boreholes (see Figure 2a for locations). The resistivity structures observed in the two studies were very similar.

\section{Comparison between the inversion model and other data}

Neutron-neutron, gamma-gamma, and natural-gamma well logs are available for all 18 boreholes. To compare the electrical variability of the aquifer with the well-log information, we compute average vertical resistivity profiles for each borehole. For this purpose, the average resistivity is calculated for a $40-\mathrm{cm}$ diameter, $20-\mathrm{cm}$-high cylindrical volume centered about the borehole and about each point. Assuming that the highest number of counts of the neutron-neutron logs represents $50 \%$ porosity and the lowest represents $12 \%$ porosity, corresponding to values estimated at the geologically similar Boise hydrogeophysical research site (Barrash and Clemo, 2002), the raw logs can be converted to approximate porosity estimates. The natural gamma log (not calibrated) gives information about the clay content (Revil et al., 1998). Figure 9 shows a comparison of the average vertical profile through the resistivity tomogram of borehole P3 with the relevant neutron-neutron (converted to porosity) and the natural gamma logs. The correlation coefficients between the average resistivity profile and well logs are -0.88 and -0.94 , respectively. The central high resistivity zone of the aquifer has a relatively low porosity and low clay content (see also Doetsch et al., 2010b), whereas the lower resistivity region at the base of the aquifer is characterized by relatively high 
porosities and high clay content, consistent with the lens of fine sediments located in this depth range (see Figure $7 \mathrm{a}$ and Results).

Electrical conductivity logs were also recorded at the site using a direct-push machine (Schulmeister et al., 2003). This system incorporated a Wenner array with an electrode spacing of $10 \mathrm{~cm}$. The measurements were progressively made as the tool was hammered into the ground. Such resistivity logs were acquired at a total of 10 different locations between the boreholes. The instrument measured the average resistivity of the earth to a radius of approximately $10 \mathrm{~cm}$ (one third of the current electrode spacing) centered about the borehole, whereas the vertical resolution was estimated to be approximately $10 \mathrm{~cm}$. Measurements were taken at 2- to 3-cm-depth intervals. Before each data set was acquired, the system was tested and calibrated. Figure 10 shows a representative vertical resistivity profile extracted from the inversion model at the same location where an electrical conductivity log was recorded. To be comparable with the lower resolution ERT profile, the log data were averaged over $40-\mathrm{cm}$-depth intervals using a running average smoother. The trends of the two data sets are similar, with a correlation coefficient of 0.73 .

a)

b)

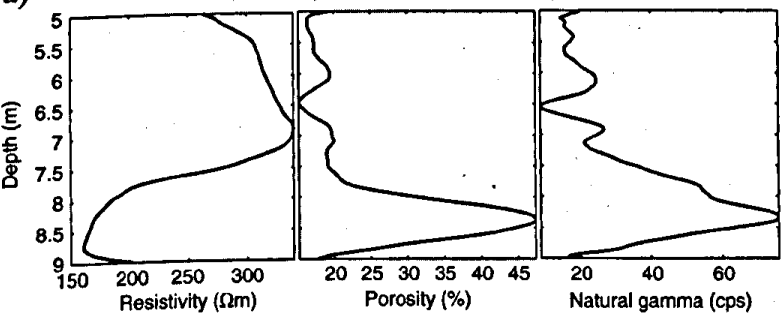

Figure 9. For borehole P3, comparison between vertical profiles of (a) resistivity extracted from the final inverted 3D model around the borehole, (b) the neutron-neutron log converted to porosity, and (c) the natural gamma log.

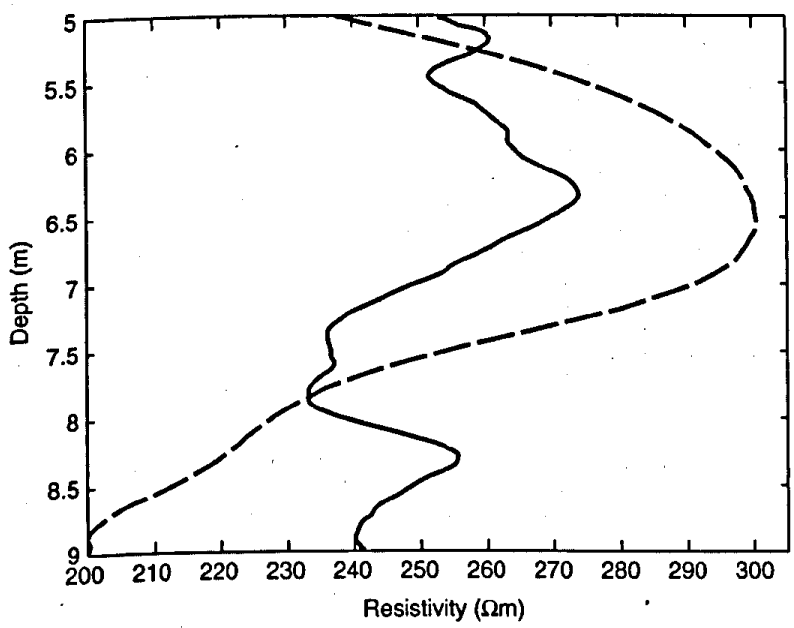

Figure 10. Example of a vertical resistivity profile extracted from the final ERT inversion model (dashed line) and a coincident resistivity log obtained with a direct-push probe system (full line).

\section{CONCLUSIONS}

We have installed a resistivity monitoring system to study the hydrogeological properties of a gravel aquifer using flood events of an adjacent river as a natural electrical tracer. Eighteen boreholes equipped with total of 180 electrodes allow continuous collection of crosshole ERT measurements that can be used in a static and dynamic sense to characterize the lithological subunits and hydraulic properties of the aquifer. We utilize an unconventional fully $3 \mathrm{D}$ data acquisition sequence that enables the collection of approximately 15,500 voltages (apparent resistivities) every $7 \mathrm{~h}$, of which roughly 11,000 are retained for the final inversions.

Approximately 1 year of ERT time series have now been acquired. They show the natural fluctuations of the water electrical properties of the adjacent infiltrating river. We have presented one example of a flood event, which produces a $15 \%$ apparent resistivity anomaly, clearly showing how the geoelectrical data contain valuable information about the river infiltration process.

We have investigated problems related to inverting a very large static crosshole ERT data set. Disconnecting the regularization across the known sharp layer boundaries (water table and gravel-clay interface) and correct positioning of the electrodes were necessary to obtain meaningful results. Including the boreholes in the inversion (i.e., the borehole-fluid effect) would have avoided generating artifacts when using more classical electrode configurations. For the unconventional circulating 3D electrode acquisition scheme used in this study, we determined that the borehole-fluid effect was not significant. Accordingly, this scheme is a viable option when computing limitations are an issue or when unstructured FEM codes are unavailable.

The 3D inversion of the chosen static ERT data set yielded a roughly three-layer gravel aquifer model with superimposed minor variations. The central zone of the model, corresponding to roughly one third of the aquifer thickness, is $50 \%$ more resistive than the upper and lower regions. The inverted model correlates with the geophysical well-log data at the site. In particular, we observe strong correlations between the resistivity and neutron-neutron (representing porosity) and natural gamma (representing clay content) logs. From these comparisons, we interpret the relatively high-resistive central zone as being of lower porosity and the relatively low-resistive lower part of the aquifer as containing a larger proportion of fine sediments. These results are consistent with those previously obtained from jointly inverted crosshole seismic, radar, and ERT data acquired over a subvolume of the experimental site.

This research forms the basis for future time-lapse ERT inversion that will be used to track preferential flow paths in the aquifer delineated by the infiltrating river water with different electrical properties and flow rates. A key challenge for the 4D imaging will be to separate the temporal effects of water table height, resistivity (salinity), and temperature variations. In fact, these three state variables, which are simultaneously sensed by the ERT data, can even have opposing effects on the data and make difficult the interpretation of the time-lapse results. To this end, we plan to investigate in detail the observed correlation between the input time series of the water height, resistivity, and temperature in the river and the output ERT time series, and then filter the data to isolate the signal of interest related to the infiltrating less saline river water. 


\section{ACKNOWLEDGMENTS}

We thank our collaborators within the RECORD project, Christoph Bärlocher for his essential contribution in building and maintaining the ERT monitoring installation, Ludovic Baron for performing borehole deviation logging, and all of the ETH undergraduate and graduate students who helped in the development of the field experiment. We acknowledge the important role played by Olaf Cirpka in the early stage of the RECORD project. The Swiss National Science Foundation (SNF) and ETH's Competence Center for Environment and Sustainability (CCES) provided funding for this study.

\section{REFERENCES}

Acworth, R. I., and W. A. Timms, 2003, Hydrogeological investigation of mud-mound springs developed over a weathered basalt aquifer on the Liverpool Plains, New South Wales, Australia: Hydrogeology Journal, 11, 659-672, doi: 10.1007/s10040-003-0278-0.

Barrash, W., and T. Clemo, 2002, Hierarchical geostatistics and multifacies systems: Boise Hydrogeophysical Research Site, Boise, Idaho: Water Resources Research, 38, $1196-1213$, doi: 10.1029/2002WR001436.

Bing, Z., and S. A. Greenhalgh, 2000, Cross-hole resistivity tomography using different electrode configurations: Geophysical Prospecting, 48, 887-912, doi: 10.1046/j.1365-2478.2000.00220.x.

Binley, A., G. Cassiani, R. Middleton, and P. Winship, 2002, Vadose zone flow model parameterisation using cross-borehole radar and resistivity imaging: Journal of Hydrology, 267, 147-159, doi: 10.1016/S00221694(02)00146-4

Blome, M., H. R. Maurer, and K. Schmidt, 2009, Advances in threedimensional geoelectric forward solver techniques: Geophysical Jouma International, 176, 740-752, doi: 10.1111/j.1365-246X.2008.04006.

Cassiani, G., V. Bruno, A. Villa, N. Fusi, and A. M. Binley, 2006, A saline trace test monitored via time-lapse surface electrical resistivity tomography: Journal of Applied Geophysics, 59, 244-259, doi: 10.1016/ j.jappgeo.2005.10.007.

Chambers, J. E., P. B. Wilkinson, A. L. Weller, P. I. Meldrum, R. D. Ogilvy, and S. Caunt, 2007, Mineshaft imaging using surface and crosshole 3D electrical resistivity tomography: A case history from the East Pennine Coalfield, UK: Journal of Applied Geophysics, 62, 324-337, doi: $10.1016 /$ j.jappgeo.2007.03.004.

Cirpka, O. A., M. N. Fienen, M. Hofer, E. Hoehn, A. Tessarini, R. Kipfer, and P. K. Kitanidis, 2007, Analyzing bank filtration by deconvoluting time series of electric conductivity: Ground Water, 45, 318-328, doi: $10.1111 / \mathrm{j} .1745-6584.2006 .00293 . x$

Crook, N., A. Binley, R. Knight, D. A. Robinson, J. Zarnetske, and R. Haggerty, 2008, Electrical resistivity imaging of the architecture of substream sediments: Water Resources Research, 44, W00D13, doi: 10.1029/2008WR006968.

Daily, W., and E. Owen, 1991, Cross-borehole resistivity tomography: Geophysics, 56, 1228-1235, doi: 10.1190/1.1443142.

Daily, W., and A. Ramirez, 1995, Electrical resistance tomography during in-situ trichloroethylene remediation at the Savannah River Site: Joumal of Applied Geophysics, 33, 239-249.

Daily, W., A. Ramirez, A. Binley, and D. LaBrecque, 2005, Electrical resistance tomography - Theory and practice: in D. K. Butler, ed., Nearsurface geophysics: SEG, 525-550.

de Franco, R., G. Biella, L. Tosi, P. Teatini, A. Lozej, B. Chiozzotto, M. Giada, F. Rizzetto, C. Claude, A. Mayer, V. Bassan, and G. Gasparetto-Stori, 2009, Monitoring the saltwater intrusion by time lapse electrical resistivity tomography: The Chioggia test site (Venice Lagoon, Italy): Journal of Applied Geophysics, 69, 117-130, doi: 10.1016/j.jappgeo. 2009.08.004.

Deiana, R., G. Cassiani, A. Kemna, A. Villa, V. Bruno, and A. Bagliani, 2007, An experiment of non-invasive characterization of the vadose zone via water injection and groundwater time-lapse geophysical monitoring: Near Surface Geophysics, 5, 183-194.

Diem, S., T. Vogt, and E. Hoehn, 2010, Spatial characterization of hydraulic conductivity in alluvial gravel-and-sand aquifers: A comparison of methods: Grundwasser (in German), 15, 241-251.

Doetsch, J. A., I. Coscia, S. Greenhalgh, N. Linde, A. G. Green, and T. Günther, $2010 \mathrm{a}$, The borehole-fluid effect in electrical resistivity imaging: Geophysics, 75, no. 4, F107-F114, doi: 10.1190/1.3467824.

Doetsch, J. A., N. Linde, I. Coscia, S. Greenhalgh, and A. G. Green, 2010b, Zonation for 3D aquifer characterization based on joint inversion of multi-method crosshole geophysical data: Geophysics, 75, no. 6, G53G64, doi: 10.1190/1.3496476.
French, H., and A. Binley, 2004, Snowmelt infiltration: Monitoring temporal and spatial variability using time-lapse electrical resistivity: Journal of Hydrology (Amsterdam), 297, 174-186, doi: 10.1016/j.jhydrol.2004. 04.005

Günther, T., 2004, Inversion methods and resolution analysis for the 2D/ $3 \mathrm{D}$ reconstruction of resistivity structures from $\mathrm{DC}$ measurements: Ph.D. thesis, Technischen Universität Bergakademie Freiberg.

Günther, T., C. Rücker, and K. Spitzer, 2006, Three-dimensional modelling and inversion of dc resistivity data incorporating topography - II: Inversion: Geophysical Journal Intemational, 166, 506-517, doi: 10.1111/j.1365-246X.2006.03011.x.

Hauck, C., 2002, Frozen ground monitoring using DC resistivity tomography: Geophysical Research Letters, 29, 2016-2019, doi: 10.1029/ 2002 GL014995.

Hayley, K., L. R. Bentley, and M. Gharibi, 2009, Time-lapse electrical resistivity monitoring of salt-affected soil and groundwater: Water Resources Research, 45, W07425, doi: 10.1029/2008WR007616.

Jayawickreme, D. H., R. L. Van Dam, and D. W. Hyndman, 2008, Subsurface imaging of vegetation, climate, and root-zone moisture interactions: Geophysical Research Letters, 35, no. 18, L18404, doi: 10.1029/
2008GL034690.

Kemna, A., B. Kulessa, and H. Vereecken, 2002, Imaging and characterisation of subsurface solute transport using electrical resistivity tomography (ERT) and equivalent transport models: Journal of Hydrology, 267, 125-146, doi: $10.1016 / \mathrm{S} 0022-1694(02) 00145-2$

Krautblatter, M., S. Verleysdonk, A. Flores-Orozco, and A. Kemna, 2010 Temperature-calibrated imaging of seasonal changes in permafrost rock walls by quantitative electrical resistivity tomography (Zugspitze, German/Austrian Alps): Journal of Geophysical Research, 115, F02003, doi: $10.1029 / 2008$ JF001209.

Kruse, S., M. Grasmueck, M. Weiss, and D. Viggiano, 2006, Sinkhole structure imaging in covered Karst terrain: Geophysical Research Letters, 33, L16405, doi: 10.1029/2006GL026975.

Kuras, O., J. D. Pritchard, P. I. Meldrum, J. E. Chambers, P. B. Wilkinson, R. D. Ogilvy, and G. P. Wealthall, 2009, Monitoring hydraulic processes with automated time-lapse electrical resistivity tomography (ALERT): Comptes Rendus Geoscience, 341, 868-885, doi: 10.1016/ j.crte.2009.07.010

LaBrecque, D. J., M. Miletto, W. Daily, A. Ramirez, and E. Owen, 1996b, The effects of noise on Occam's inversion of resistivity tomography data: Geophysics, 61, 538-548, doi: 10.1190/1.1443980.

LaBrecque, D. J., A. L. Ramirez, W. D. Daily, A. M. Binley, and S. A. Schima, 1996a, ERT monitoring on environmental remediation processes: Measurement Science \& Technology, 7, 375-383, doi: 10.1088/

Lane, J. W. Jr., F. D. Day-Lewis, and C. C. Casey, 2006, Geophysical monitoring of a field-scale biostimulation pilot project: Ground Water 44, 430-443, doi: $10.1111 / j .1745-6584.2005 .00134 . x$.

Linde, N., A. Binley, A. Tryggvason, L. B. Pedersen, and A. Revil, 2006, Improved hydrogeophysical characterization using joint inversion of cross-hole electrical resistance and ground-penetrating radar traveltime data: Water Resources Research, 42, W12404, doi: 10.1029/ 2006WR005131.

Maurer, H., S. Friedel, and D. Jaeggi, 2009, Characterization of a coastal aquifer using seismic and geoelectric borehole methods: Near Surface Geophysics, 7, 353-366.

Miller, C. R., P. S. Routh, T. R. Brosten, and J. P. McNamara, 2008 Application of time-lapse ERT imaging to watershed characterization: Geophysics, 73, no. 3, G7-G17, doi: 10.1190/1.2907156.

Müller, K., J. Vanderborght, A. Englert, A. Kemna, J. A. Huisman J. Rings, and H. Vereecken, 20l0, Imaging and characterization of solute transport during two tracer tests in a shallow aquifer using electrical resistivity tomography and multilevel groundwater samplers: Water Resources Research, 46, no. 3, W03502, doi: 10.1029/2008WR007595.

Nimmer, R. E., J. L. Osiensky, A. M. Binley, K. F. Sprenke, and B. C. Williams, 2007, Electrical resistivity imaging of conductive plume dilution in fractured rock: Hydrogeology Journal, 15, 877-890, doi 10.1007/s10040-007-0159-z

Nyquist, J. E., P. A. Freyer, and L. Toran, 2008, Stream bottom resistivity tomography to map ground water discharge: Ground Water, 46, 561569, doi: $10.1111 / \mathrm{j} .1745-6584.2008 .00432 . x$.

Ogilvy, R. D., P. I. Meldrum, O. Kuras, P. B. Wilkinson, J. E. Chambers, M. Sen, A. Pulido-Bosch, J. Gisbert, S. Jorreto, I. Frances, and P. Tsourlos, 2009, Automated monitoring of coastal aquifers with electrical resistivity tomography: Near Surface Geophysics, 7, 367-375.

Ramirez, A., W. Daily, D. LaBrecque, E. Owen, and D. Chesnut, 1993 Monitoring an underground steam injection process using electrical-resistance tomography: Water Resources Research, 29, 73-87, doi: $0.1029 / 92$ WR 01608

Revil, A., L. M. Cathles III, S. Losh, and J. A. Nunn, 1998, Electrical conductivity in shaly sands with geophysical applications: Journal of Geophysical Research, 103, 23925-23936, doi: 10.1029/98JB02125. 
Robinson, D. A., A. Binley, N. Crook, F. D. Day-Lewis, T. P. A. Ferré, V. J. S. Grauch, R. Knight, M. Knoll, V. Lakshmi, R. Miller, J. Nyquist, L. Pellerin, K. Singha, and L. Slater, 2008, Advancing process-based watershed hydrological research using near-surface geophysics: A vision for, and review of, electrical and magnetic geophysical methods: Hydrological Processes, 22, 3604-3635, doi: 10.1002/hyp.6963.

Rücker, C., T. Günther, and K. Spitzer, 2006, Three-dimensional modelling and inversion of dc resistivity data incorporating topography - I. Modelling: Geophysical Journal International, 166, 495-505, doi: 10.1111/j.1365-246X.2006.03010.x.

Schulmeister, M. K., J. J. Butler Jr., J. M. Healey, L. Zheng, D. A Wysocki, and W. McCall, 2003, Direct-push electrical conductivity logging for high-resolution hydrostratigraphic characterization: Ground ging for high-resolution hydrostratigraphic characterization: Ground 6592.2003.tb00683.x.

Singha, K., and S. M. Gorelick, 2005, Saline tracer visualized with threedimensional electrical resistivity tomography: Field-scale spatial moment analysis: Water Resources Research, 41, W05023, doi: 10.1029/2004WR003460.

Sjödahl, P., T. Dahlin, and S. Johansson, 2009, Embankment dam seepage evaluation from resistivity monitoring data: Near Surface Geophysics, $7,463-474$
Slater, L. D., and A. M. Binley, 2006, Synthetic and field-based electrical imaging of a zerovalent iron barrier: Implications for monitoring longterm barrier performance: Geophysics, 71, no. 5, B129-B137, doi: $10.1190 / 1.2235931$.

Slater, L., A. M. Binley, W. Daily, and R. Johnson, 2000, Cross-hole electrical imaging of a controlled saline tracer injection: Journal of Applied Geophysics, 44, 85-102, doi: 10.1016/S0926-9851(00)00002-1.

Slater, L. D., and S. K. Sandberg, 2000, Resistivity and induced polarization monitoring of salt transport under natural hydraulic gradients: Geophysics, 65, 408-420, doi: 10.1190/1.1444735.

Ward, A. S., M. N. Gooseff, and K. Singha, 2010, Imaging hyporheic zone solute transport using electrical resistivity: Hydrological Processes, 24, 948-953, doi: $10.1002 / \mathrm{hyp} .7672$

Wilkinson, P. B., P. I. Meldrum, O. Kuras, J. E. Chambers, S. J. Holyoake, and R. D. Ogilvy, 2010, High-resolution Electrical Resistivity Tomography monitoring of a tracer test in a confined aquifer: Journal of Applied Geophysics, 70, 268-276, doi: 10.1016/j.jappgeo. 2009.08.001

Yeh, T. C. J., C. H. Lee, K. C. Hsu, W. A. Illman, W. Barrash, X. Cai, J. Daniels, E. Sudicky, L. Wan, G. M. Li, and C. L. Winter, 2008, A view toward the future of subsurface characterization: CAT scanning groundwater basins: Water Resources Research, 44, W03301, doi: 10.1029/2007WR006375. 